\title{
The Anatomical Basis of the Vascularized Fibularis Brevis Grafts
}

\author{
Base Anatómica de los Injertos Vascularizados del Músculo Fibularis Brevis
}

Wagih G. Elbarrany \&Wardah A. Alasmari

ELBARRANY, W. G. \& ALASMARI, W.A. The anatomical basis of the vascularized fibularis brevis grafts. Int. J Morphol., 36(3):848$853,2018$.

SUMMARY: Fibularis brevis grafts have been extensively used, especially as distally-based grafts, to cover defects in the lower leg and foot. The study has contributed to analyze the blood supply of the fibularis brevis muscle and the vascular basis of its possible different grafts. Both legs of twelve preserved cadavers, without congenital vascular anomalies, were utilized in the study. Fibularis brevis was exposed in all selected legs along with the verification of different arterial pedicles. The total means and standard deviations of the length and width of the muscle together with diameters of major vessels were calculated. Total length and width of middle portion of fibularis brevis were at means of $28.7 \pm 0.4 \mathrm{~cm}$ and $3 \pm 0.02 \mathrm{~cm}$ respectively. The upper and middle portions of the muscle were supplied by the fibular and the anterior tibial artery. The middle portion was supplemented by the upper perforating branch of the posterior tibial artery. The lower portion of the muscle was supplied by the lower perforating branch of the posterior tibial and the periosteal arteries. The muscle could be used as a proximally or distally based flap, free vascularized muscle graft, free vascularized osteo-muscular flap, and distally-based split flap. It can be split completely into two flaps; each of which can be used as a proximally or distally.

KEY WORDS: Fibularis brevis muscle; Fibular artery; Distally-based grafts; Free vascularized graft; Anterior tibial artery.

\section{INTRODUCTION}

The anatomical features have presented that the peoneal artery vascularizes fibularis gravis muscles. In 90 $\%$ of leg, cutaneous artery is originated from fibular artery within $2 \mathrm{~cm}$ of the fibular midpoint. The vessel facilitates and acts as a monitor of vascularity for skin loss, and also allows transferring of skin along with bone. Skin defects, especially large defects with bone exposure, in the lower leg represent a major challenge for treatment. Local and free flaps could help reconstruction of such defects. The use of distally based fibularis brevis muscle flap can be effective with much less mortality and morbidity as compared to free muscle flaps especially for moderate and small defects. Many surgical procedures were described to cover defects in the lower third of the leg such as muscle trans-positional flaps, adipo-fascial flaps, and reverse-sural flaps. However, none proved ideal local-flaps (Hallock, 1991; Lai et al., 1992; Arnold et al., 1999; Hallock, 2000; Singh \& Naasan, 2001; Price et al., 2002) due to the exposed bones and condensed lower leg tendons.

Mathes \& Nahai (1981) had classified the individual muscles according to their blood supply into five types. Type I muscle flaps are defined by a single vascular pedicle, while type II muscle flaps represent a dominant pedicle(s) and minor pedicle(s). Type III muscle flaps have 2 dominant pedicles, and the type IV muscle flap has segmented vascular pedicles. Finally, type $\mathrm{V}$ muscle flaps correspond to a single dominant pedicle and secondary segmental pedicles (Mathes $\&$ Nahai). It was also reported that most muscles in the lower leg are of type IV, which is considered to be the least mobile muscles. The fibularis brevis muscle was first classified as Type II then reclassified as Type IV (Mathes \& Nahai; Yang, et al., 2005).

Reconstruction of defects in the distal third of the leg using local procedures is not always successful as relative deficiency of reliable local flaps, and their small radius of extension in distal direction (Benito-Ruiz et al., 2004). Consequently, free vascularized tissue grafts are usually considered as the treatment of choice to cover large lower leg defects. However, it needs experience in micro vascular anastomosis and also the healthy sizable vessels of the transferred tissue and the recipient sites (Gonzalez et al., 2002). The distally pedicle fibularis brevis muscle flap is proved to be more helpful to cover these defects and can reach areas distal to the lateral malleolus (Eyssel \& Dresing, 
1989; Eren et al., 2001; Koski et al., 2005; Yang et al.). Fibularis brevis was reported to be used as a functional component of osteomyo-cutaneous flap in the reconstruction of severe injury of the upper limb. They utilized its segmental blood supply from the anterior tibial and fibular arteries, and its single motor nerve that enters the muscle at its proximal end. Donor complication in this case was reported to be absent (Giessler \& Schmidt, 2013). Therefore, the present study was planned to study the arterial pedicles to the fibularis brevis muscle along with its possible importance in planning of different arterial pedicle flaps of the muscle.

\section{MATERIAL AND METHOD}

Both legs of twelve preserved cadavers, without obvious congenital vascular anomalies, were used in the current study. A vertical skin incision was done in the middle line of the posterior aspect of each leg. The skin was reflected on both sides of the incision. The calcaneal tendon (Achilles tendon) was identified and was transversely cut. The soleus and gastrocnemius muscles were then reflected upwards to expose the posterior tibial artery. Branches of the posterior tibial artery were then identified specially the fibular and the fibular arteries. The latter was identified, and its relation to the flexor hallucis longus muscle was verified. The skin flap was reflected on more laterally to expose the fibular compartment. Fibularis longus muscle was dissected to identify the arterial pedicles that supply the fibularis brevis muscle, and then it was removed to expose the whole length of the fibularis brevis muscle. The muscle was then removed to measure the fleshy and tendinous portions together with the width of its fleshy part. The length of the leg was also measured from the middle of the knee joint cavity till the tip of the lateral malleolus. Swiss Vernier caliber (of 0.05 mm accuracy) was used to calculate the diameters of the major blood vessels especially the fibular artery. Statistical analysis of the data obtained was calculated using the mean values and the standard deviation.

\section{RESULTS}

The total length of the fibularis brevis was at a mean of $28.7 \pm 0.4 \mathrm{~cm}$ (ranging from 24 to $32 \mathrm{~cm}$ ). The length of its tendon was at an average of $8 \pm 0.1 \mathrm{~cm}$ (ranged from 6.8 to $9.3 \mathrm{~cm}$ ). The width of the middle third of it was at a mean of $3 \pm 0.02 \mathrm{~cm}$ (ranging from 2.5 to $3.5 \mathrm{~cm}$ ), while upper and lower thirds had an average width of $2.3 \pm 0.04 \mathrm{~cm}$ (ranged from 2 to $3.5 \mathrm{~cm}$ ). The total leg length was at a mean of $38.8 \pm 0.6 \mathrm{~cm}$ (ranging from 32 to $43 \mathrm{~cm}$ ).
The upper portion of the medial part of fibularis brevis muscle got arterial pedicles from the anterior tibial artery. The artery gave two branches; the larger one accompanied the superficial fibular artery that penetrated the fibularis muscle at a mean distance of distance of $18.7 \pm 0.2 \mathrm{~cm}$ (ranging from 14.8 to 21) from the lateral malleolus. The other pedicle accompanied an additional nerve to the fibularis brevis muscle. The lateral portion of the middle and lower parts of the muscle got multiple arterial pedicles from the fibular artery and the lower perforating branch of the posterior tibial artery (Fig. 1).

The fibular artery pierced the posterior intermuscular septum (18.8 cm from lateral malleolus; ranged from 14 to 23 ), and passed between the fibularis longus and brevis. Its external diameter at its origin from the posterior tibial was at a mean of $2.1 \pm 0.02 \mathrm{~mm}$ (ranging from 1.3 to $3.2 \mathrm{~mm}$ ). It passed for a mean distance of $14 \pm 0.12 \mathrm{~cm}$ (ranged from 11 to $16 \mathrm{~cm}$ ); it penetrated the fibularis brevis at a mean distance of $16 \pm 0.34 \mathrm{~cm}$ (ranged from 11 to $18 \mathrm{~cm}$ ) from the lateral malleolus. It ended by anastomosing of a perforating branch of the posterior tibial artery in nearly $90 \%$ (10 cases) of the studied cases (Figs. 1C-D). The perforating branch perforated the posterior inter-muscular septum at a mean distance of $4 \pm 0.04 \mathrm{~cm}$ (ranged from 3 to $5 \mathrm{~cm}$ ) from the lateral malleolus. Its external diameter was at a mean of $1.2 \pm 0.01 \mathrm{~mm}$ (ranging from 0.9 to $1.5 \mathrm{~mm}$ ). In $10 \%$ of the cases, the artery ended in fibularis brevis without visible macroscopic anastomosis with the perforating branch of the posterior tibial artery. The fibular artery supplied the fibularis brevis and longus muscles and the fibula; it gave branches to anastomose with the arterial pedicles of the anterior tibial artery (Fig. 1A).

The middle portion of the muscle got arterial pedicle from the upper perforating branches of the posterior tibial artery that perforated the posterior inter-muscular septum (Fig. 2A). The lower portion of the muscle, together with its tendon, received vascular branches from the periosteal arteries of the fibula, branches from adjacent vessels and muscles (Figs. 2. B-D). The total number of arterial pedicles to fibularis brevis was at a mean of 5 pedicles (ranged 4-6 pedicles). These were shared by the anterior tibial, fibular and posterior tibial arteries in $90 \%$ of the studied legs.

The fibularis muscle was supplied by the fibular artery that can be elevated with it to get a vascularized free muscle graft. Moreover, the musclecan be used as distallybased muscle flap depending on the perforating branch of the posterior tibial artery. Similarly, it can be used as proximally-based muscle graft depending on the fibular artery. The muscle can be divided into two complete halves; each can be used as a proximally or distally based muscle graft or half of the muscle can be used only as a muscle 

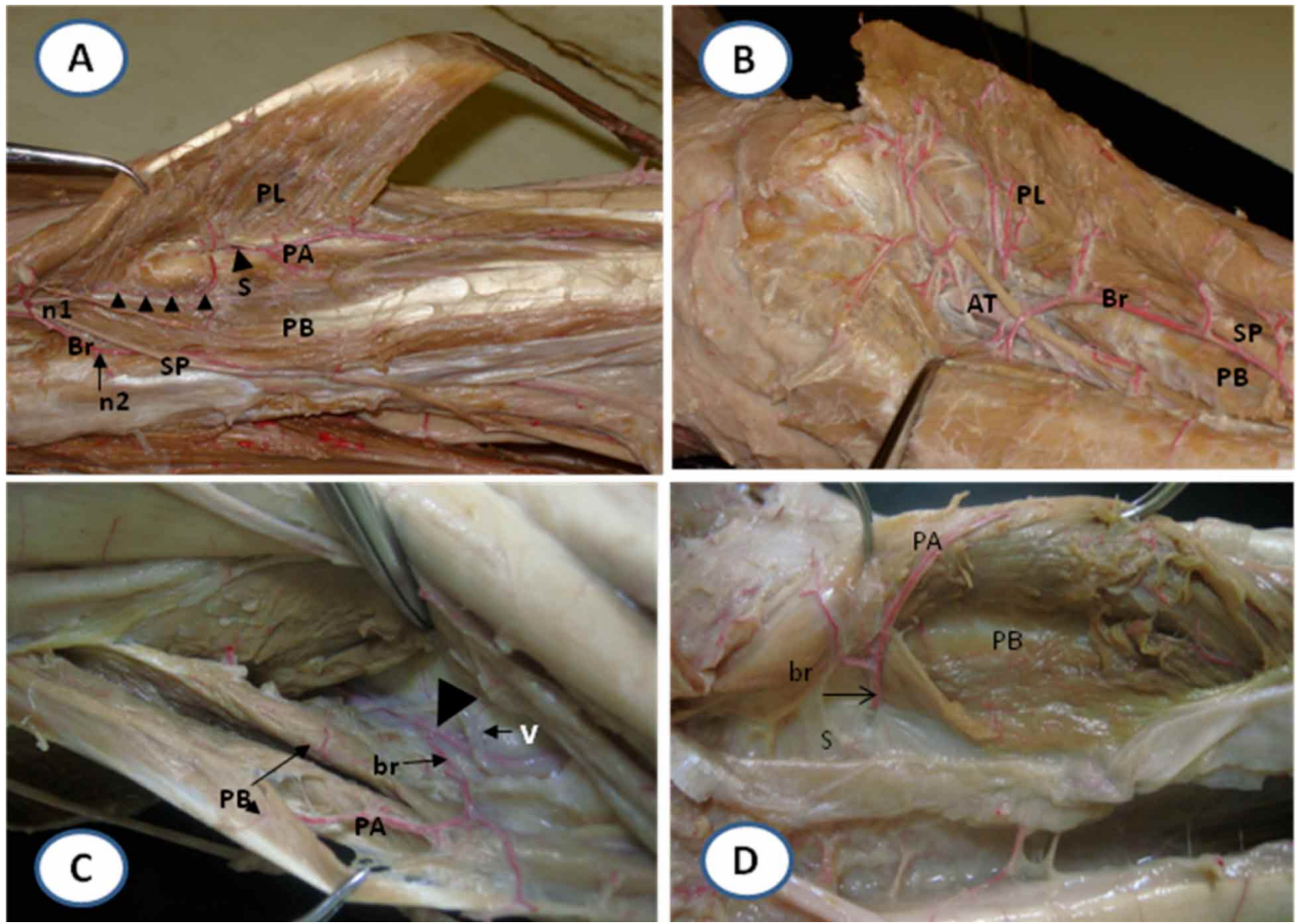

Fig. 1. 1A - B. The fibularis brevis muscle (PB) gets arterial pedicles (p) from the anterior tibial artery (AT); it accompanies the superficial fibular nerve (SP). The fibular artery (PA) pierces the posterior inter-muscular septum at (S) passes between the muscles fibularis longus and brevis (PL, PB). It anastomoses with the branches of the anterior tibial artery (arrowheads) that accompany the second nerve supply (N2) to the fibularis brevis. 1C - 1D. The terminal part of fibular artery (PA) continues to anastomose with the lower (distal) perforating branch (b) arising from the posterior tibial artery (arrow).
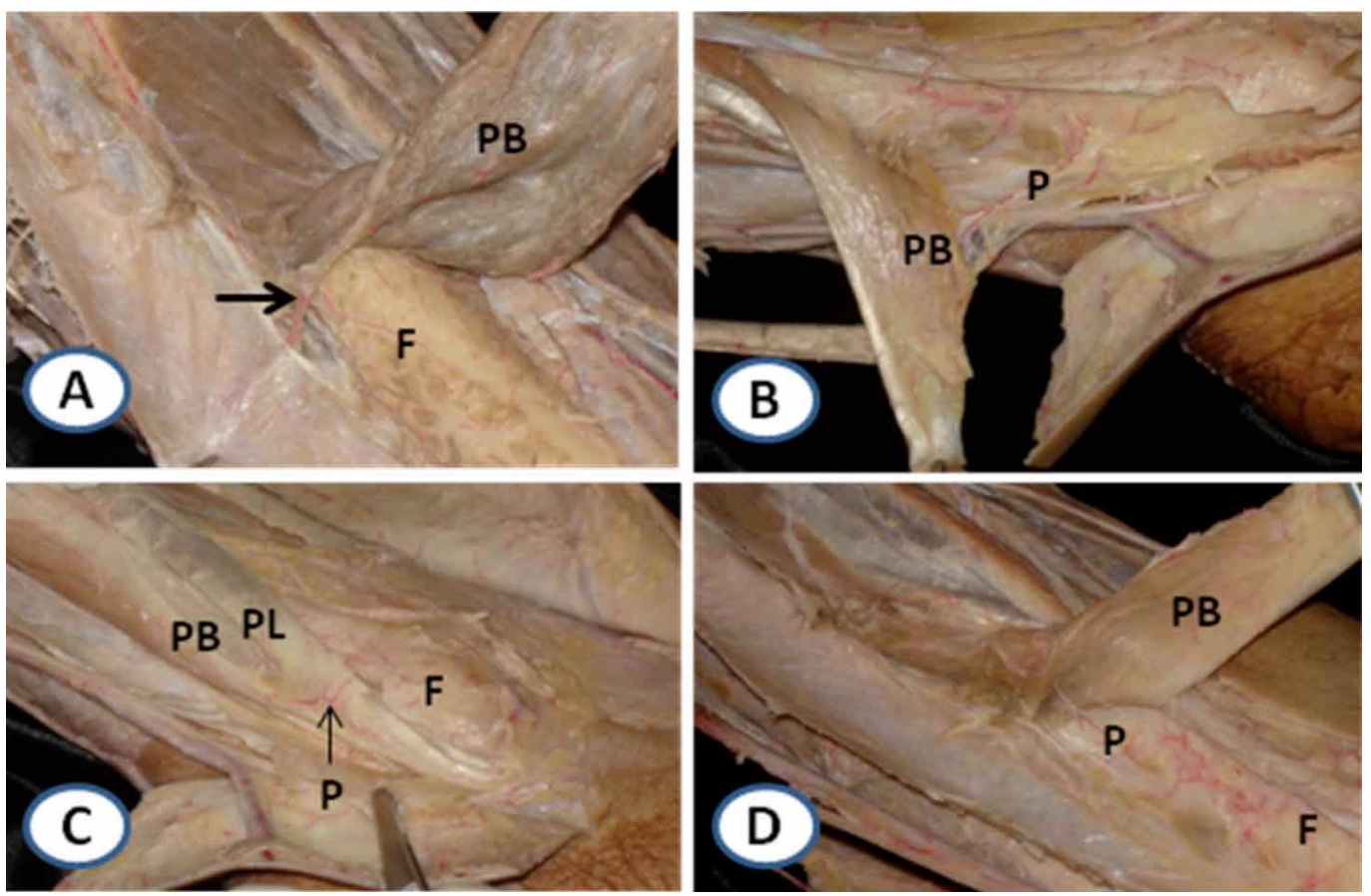

Fig.2. A. The proximal perforating artery (thick arrow) of the posterior tibial artery penetrates the septum to supply fibularis brevis muscle (PB). B, C , D: periosteal branches $(\mathrm{P})$ supply the distal part of fibularis brevis muscle (PB) and its tendon. PL; fibularis longus, F; fibula 

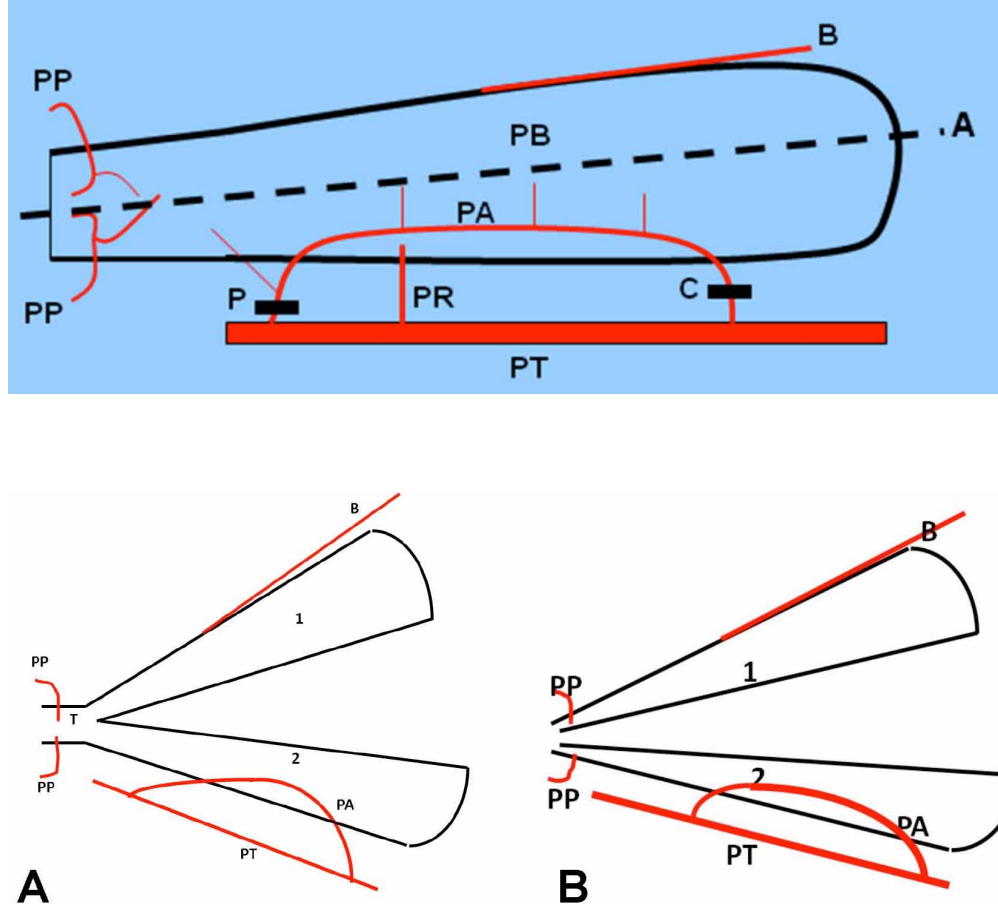

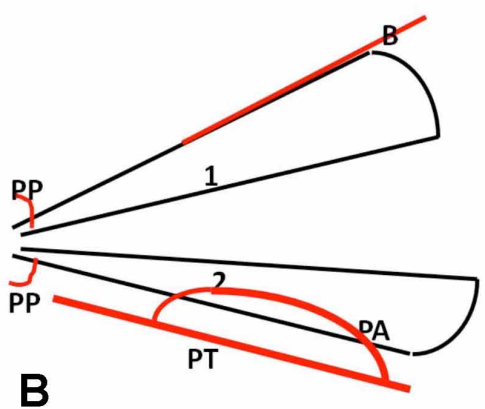

Fig. 3. A diagrammatic illustration of the blood supply to fibularis brevis muscle (PB). Fibular artery (PA) arises from posterior tibial artery (PT) to supply the medial portion of fibularis muscle and anastomoses with the distal perforating branch $(\mathrm{P})$. The muscle can be elevated with the fibular artery as a free vascularized muscle flap. The lateral portion of the muscle is supplied by branches (B) from the anterior tibial artery. The muscle can be silted into two vascularized halves (the dotted line). The lower portion of the muscle with its tendon are supplied by periosteal branches of the fibula (PP).

Fig. 4. A. shows splitting of the fleshy portion of the fibularis brevis $(1,2)$ with intact tendon $(\mathrm{T})$ for distally-based split graft. B. shows complete division of fibularis brevis into two halves $(1,2)$; each can be used as a proximally- or distally-based vascularized graft. B; anterior tibial artery, PA; fibular artery. PT; posterior tibial artery. PP; periosteal branches. graft sparing the other half or the fleshy part is divided leaving intact tendon for distally-based split graft (Figs. 3 and 4). The muscle got arterial pedicles from the anterior tibial, fibular and posterior tibial arteries in twenty of the studied cases $(85 \%)$.

\section{DISCUSSION}

The distally based fibularis brevis muscle flap is a reliable alternative for covering defects in the ankle region. Several studies on the clinical application of this muscle flap have shown appropriate outcomes (McHenry, 2001; Bach et al., 2007; Ng et al., 2010). Moreover, reported cases of its use as a composite distally pedicle osteo-muscular flap permitting individual placement of a middle fibula segment (Giessler \& Schmidt). The study has illustrated that the fibularis brevis got its blood supply from three sources; the anterior tibial, posterior tibial, and fibular arteries. The anterior tibial artery branches supplied the upper and middle portions of the medial (anterior or dorsal) side of the muscle. Its arterial pedicle passed with the superficial fibular nerve and the nerve to the muscle. The fibular artery supplied the upper and middle portions of the muscle, and its periosteal branches supplied the lower part together with the periosteal branches of the posterior tibial artery. Its upper branches anastomosed with those of the anterior tibial artery. The middle portion of the muscle got additional supply from the proximal perforating branch of the posterior tibial artery. The distal perforating branch and the periosteal branches of the posterior tibial artery supplied the lower portion of the muscle as it penetrated about $4 \mathrm{~cm}$ above the tip of the lateral malleolus. The study also showed that the fibular artery was the main blood supply to the lateral (posterior or ventral) portion of the muscle while the anterior tibial is main blood supply to the medial (anterior) portion of the muscle. Consequently, the muscle is considered to have two main principal arterial pedicles, regarding the diameters of vessels, which have not matched with the outcomes of other researchers (Villarreal et al., 2004), who considered the anterior tibial artery as main principal artery and the fibular artery as supplementary vessel. A study reported that the muscle gets arterial supply from two sources only; the anterior tibial and the fibular arteries (Ensat, 2015). In this study, the posterior tibial artery has shared its blood supply to fibularis brevis muscle through its two perforating branches and its periosteal branches to the lower part of fibula.

The current study also showed that the fibularis brevis muscle can be vascularized with the fibular artery in $90 \%$ of cases, and can be used as a free vascularized muscle flap. The sizable diameter of the fibular artery would be suitable of micro-vascular anastomosis. Such a flap can be used in reconstruction of soft tissue defects in different areas of the body. It can be elevated with fibula as free vascularized osteo-muscular flap as the fibular artery 
supplies the fibula too. The fibularis brevis can also be used as a proximally based muscle graft depending on the fibular artery and anterior tibial artery branches to reconstruct defects around the knee or pretibial defects (Pers et al., 2009). The flap components are dependent on the fibular vessels, and were used to reconstruct extensive radial and soft-tissue defects in a severely damaged forearm. However, the fibularis brevis nerve was coopted to the proper flexor carpi radialis (FCR) motor nerve to counterbalance ulnar abduction, as all radial abductors were lost in the injury.

According to the findings, the fibularis brevis muscle can be split into two portions along its longitudinal axis; each portion will get its separate arterial supply. The medial (anterior or dorsal) portion gets supply from the anterior tibial artery and the periosteal branches, while the lateral (posterior or ventral) portion get from the fibular artery, perforating branch of the posterior tibial and the periosteal branches. Such anatomical distribution of the blood supply can be the anatomical bases of fibularis brevis muscle flap, which the author considers to be ideally suited for moderate to large defects in the distal third of the lower leg and ankle. They reported that such modified flap can cover large defects of up to $12 \times 10 \mathrm{~cm}$ in the distal leg and ankle region (Abd-Al Moktader, 2016). The two portions of the muscle can be used separately as each had its own blood supply. Moreover, the study showed that each portion can be used as a proximally or distally based muscle graft. Such a design can give the surgeon the opportunity to choose and cover different defects at different areas simultaneously.

The distally-based fibularis brevis muscle flap proved to be a reliable flap, and have been used extensively to cover defects in the lower leg and foot with successful clinical outcome (Barr et al., 2002; Saydam et al., 2002). Such flap will depend mainly on the anastomosis between the perforating branch of the posterior tibial artery and the fibular artery. Being sizable, such anastomosis can support the distally based flaps with reliability and consequent successful outcome. The distally-based fibularis brevis flap also can depend on the perforating branch of the posterior tibial artery and the periosteal branches of the fibula as shown in the current work. One of the major problems in these flaps is their venous return, which can result in post-operative edema and can result in complications. Such a problem does not change opinions of reconstructive surgery that it is the most valuable flap for reconstruction defects in the lower leg and foot (Hallock, 1991; Arnold; Gonzalez et al.; Benito-Ruiz et al.). However, it was reported recently that applying post-operative negative pressure therapy (75 $\mathrm{mmHg}$ ) has a significant effect in reducing the postoperative complication of the flap (Erne et al., 2016).
The study has also shown that the fibularis brevis muscle gets two main principal arterial pedicles from the anterior tibial and the fibular artery in addition to other small pedicles, which is in agreement with Villarreal et al. Consequently, it seems that the vascular pattern of the muscle is very near to Type III classification according Mathes \& Nahai classification. The fibular artery was the dominant arterial pedicle for the muscle for its lateral (posterior) portion supplying its upper, middle and lower parts (through its periosteal branches) of fibularis brevis. The anterior tibial artery was the dominant arterial pedicle to the medial (or anterior) portion of the muscle supplying its upper and middle regions. Incorporation of the fibularis brevis tendon allograft to restore the anatomy of the labrum and also its function without morbidity at the donor site has been reported. The tendon has been used for reconstruction of non-repairable labrum lesions located in the posterior aspect of the acetabulum and massive reconstructions in cases of global-pincer femur-acetabulum impingement and protrusion-acetabuli (Moya et al., 2016).

The current study showed that the perforating branches of the posterior and anterior tibial arteries that supplied the fibularis brevis passed through tough membranes. Consequently, local vascularized grafts of fibularis brevis cannot depend adequately on these perforating branches since rotation of the flaps may jeopardize their blood supply. These perforating branches can be kinked or damaged during rotation of local flaps. The fibularis brevis vascularized grafts can depend safely on the direct supply from the fibular and anterior tibial arteries.

\section{CONCLUSION}

It has been concluded that fibularis brevis can be used as a distally-based flap, a proximally-based flap, as a distallybased split flap. It can be also considered as a free vascularized muscle graft in $90 \%$ of the cases. It can also be completely split into two halves; each can be used as a proximally or distally based flaps. It can be further used as a composited vascularized free flap or distally based osteo muscular flap with the fibula. For average to major defects in the distal third part of lower leg and ankle, the splitting of distally based fibularis brevis muscle flap is recommended. It is challenging for the plastic surgeon if the defects in lower leg and ankle are remarkable and large. For small defects, the fibularis brevis muscle flap has played an important role and has been entrenched as very important in reconstructive procedures of the lower leg. Initially, the fibularis brevis muscle flap was explained as a proximally based flap for pre-tibial defects. 
ELBARRANY, W. G. \& ALASMARI, W. A. Base anatómica de los injertos vascularizados del músculo fibularis brevis. Int. J. Morphol., 36(3):848-853, 2018.

RESUMEN: Los injertos de músculo fibularis brevis son usados ampliamente, especialmente como injertos de base distal, para cubrir defectos en la parte inferior de la pierna y el pie. El objetivo de este estudio fue analizar el suministro de sangre del músculo fibularis brevis y la base vascular de los posibles diferentes injertos. Para el estudio se utilizaron ambas piernas de 12 cadáveres preservados, sin anomalías vasculares congénitas. El músculo fibularis brevis fue encontrado en todas las piernas junto con los diferentes pedículos arteriales. Se calcularon las medias totales y las desviaciones estándar de la longitud y el ancho del músculo, junto con los diámetros de los vasos principales. La longitud y el ancho totales de la porción media del músculo fibularis brevis fueron de $28,7 \pm 0,4 \mathrm{~cm}$ y $3 \pm 0,02 \mathrm{~cm}$, respectivamente. Las partes superior y media del músculo estaban suplidas vascularmente por la arteria fibular y la arteria tibial anterior. La parte media se complementó con la rama perforante superior de la arteria tibial posterior. La parte inferior del músculo fue suplida por una rama perforante inferior de la arteria tibial posterior y las arterias periósticas. El músculo podría usarse como un colgajo de base proximal o distal, injerto de músculo vascularizado libre, colgajo osteomuscular vascularizado libre y colgajo dividido distal. Se puede dividir por completo en dos colgajos; cada uno de estos puede ser utilizado como proximal o distal.

PALABRAS CLAVE: Músculo fibularis brevis; Arteria fibular; Injertos distales; Injerto vascularizado libre; Arteria tibial anterior.

\section{REFERENCES}

Abd-Al Moktader, M. A. Open-book splitting of a distally based fibularis brevis muscle flap to cover large leg and ankle defects. Plast. Reconstr. Surg. Glob. Open, 3(12):e572, 2016.

Arnold, P. G.; Yugueros, P. \& Hanssen, A. D. Muscle flaps in osteomyelitis of the lower extremity: a 20-year account. Plast. Reconst. Surg., 104(1):107-10, 1999.

Bach, A. D.; Leffler, M.; Kneser, U.; Kopp, J. \& Horch, R. E. The versatility of the distally based fibularis brevis muscle flap in reconstructive surgery of the foot and lower leg. Ann. Plast. Surg., 58(4):397-404, 2007.

Barr, S. T.; Rowley, J. M.; O’Neill, P. J.; Barillo, D. J. \& Paulsen, S. M. How reliable is the distally based fibularis brevis muscle flap? Plast. Reconstr. Surg., 110(1):360-2, 2002.

Benito-Ruiz, J.; Yoon, T.; Guisantes-Pintos, E.; Monner, J. \& SerraRenom, J. M. Reconstruction of soft-tissue defects of the heel with local fasciocutaneous flaps. Ann. Plast. Surg., 52(4):380-4, 2004.

Ensat, F.; Weitgasser, L.; Hladik, M.; Larcher, L.; Heinrich, K.; Skreiner, A.; Russe, E.; Fuerntrath, F.; Kamp, J.; Cotofana, S. \& Wechselberger, G. Redefining the vascular anatomy of the fibularis brevis muscle flap. Microsurgery, 35(1):39-44, 2015.

Eren, S.; Ghofrani, A. \& Reifenrath, M. The distally pedicled fibularis brevis muscle flap: a new flap for the lower leg. Plast. Reconstr. Surg., 107(6):1443-8, 2001

Erne, H.; Schmauss, D.; Schmauss, V. \& Ehrl, D. Postoperative negative pressure therapy significantly reduces flap complications in distally based fibularis brevis flaps: Experiences from 74 cases. Injury, 47(6):1288-92, 2016.

Eyssel, M. \& Dresing, K. The fibularis brevis muscle flap-plasty. A simple procedure for covering fibular soft tissue defects after osteosynthesis. Unfallchirurg, 92(2):85-91, 1989.

Giessler, G. A. \& Schmidt, A. B. The functional fibularis brevis as a third muscle component in the osteomyocutaneous fibula free-flap system. J. Plast. Reconstr. Aesthet. Surg., 66(5):e137-40, 2013.

Gonzalez, M. H.; Tarandy, D. I.; Troy, D.; Phillips, D. \& Weinzweig, N. Free tissue coverage of chronic traumatic wounds of the lower leg. Plast. Reconstr. Surg., 109(2):592-600, 2002.

Hallock, G. G. Complications of 100 consecutive local fasciocutaneous flaps. Plast. Reconstr. Surg., 88(2):264-8, 1991.

Hallock, G. G. Utility of both muscle and fascia flaps in severe lower extremity trauma. J. Trauma, 48(5):913-7, 2000.

Koski, E. A.; Kuokkanen, H. O. \& Tukiainen, E. J. Distally-based fibularis brevis muscle flap: a successful way of reconstructing lateral soft tissue defects of the ankle. Scand. J. Plast. Reconstr. Surg. Hand Surg., 39(5):299-301, 2005.

Lai, C. S.; Lin, S. D. \& Chou, C. K. Clinical application of the adipofascial turnover flap in the leg and ankle. Ann. Plast. Surg., 29(1):70-5, 1992.

Mathes, S. J. \& Nahai, F. Classification of the vascular anatomy of muscles: experimental and clinical correlation. Plast. Reconstr. Surg., 67(2):17787, 1981.

McHenry, T. P.; Early, J. S. \& Schacherer, T. G. Fibularis brevis rotation flap: anatomic considerations and clinical experience. J. Trauma, 50(5):922-6, 2001.

Moya, E.; Natera, L. G.; Cardenas, C.; Astarita, E.; Bellotti, V. \& Ribas, M. Reconstruction of massive posterior nonrepairable acetabular labral tears with Fibularis brevis tendon allograft: arthroscopy-assisted miniopen approach. Arthrosc. Tech., 5(5):e1015-e1022, 2016.

Ng, Y. H.; Chong, K. W.; Tan, G. M. \& Rao, M. Distally pedicled fibularis brevis muscle flap: a versatile lower leg and foot flap. Singapore Med. J., 51(4):339-42, 2010.

Pers, M.; Medgyesi, S. \& Kirkby, B. Fibularis brevis Muscle Flap. In: Strauch, B.; Vasconez, L. O.; Hall-Findlay, E. J. \& Lee, B. T. (Eds.). Grabb's Encyclopedia of Flaps. $3^{\text {rd }}$ ed. Philadelphia, Lippincott Williams \& Wilkins, 2009. pp.1408-9.

Price, M. F.; Capizzi, P. J.; Watterson, P. A. \& Lettieri, S. Reverse sural artery flap: caveats for success. Ann. Plast. Surg., 48(5):496-504, 2002.

Saydam, M.; Yilmaz, S. \& Seven, E. Distal fibularis brevis muscle flap. Plast. Reconstr. Surg., 110(1):351, 2002.

Singh, S. \& Naasan, A. Use of distally based superficial sural island artery flaps in acute open fractures of the lower leg. Ann. Plast. Surg., 47(5):505-10, 2001.

Villarreal, P. M.; Monje, F.; Gañán, Y.; Junquera, L. M. \& Morillo, A. J. Vascularization of the peroneal muscles. Critical evaluation in fibular free flap harvesting. Int. J. Oral Maxillofac. Surg., 33(8):792-7, 2004.

Yang, Y. L.; Lin, T. M.; Lee, S. S.; Chang, K. P. \& Lai, C. S. The distally pedicled fibularis brevis muscle flap anatomic studies and clinical applications. J. Foot Ankle Surg., 44(4):259-64, 2005.

\section{Corresponding author:}

Wagih Gamal Eldin Elbarrany

Professor of Anatomy and Embryology

Umm Al-Qura University

Makkah

SAUDI ARABIA

Email: elbarrany@yahoo.com

Received: $19-03-2018$

Accepted: 07-05-2018 